\title{
Occurrence of Proteinuria and it's Predisposing Factors among Pregnant Women Attending Antenatal Care Clinic at St. Francis Hospital Nsambya.
}

\author{
journal of gynecology and obstetrics@SJHR-Africa.
} John Edward Munyagaa,1,2, David Serunjogia,3

a Department of Health Sciences, University of Kisubi, Kisubi, Uganda

\begin{abstract}
Background:
Proteinuria refers to a condition where more than trace amounts of proteins are found in normal urine Proteinuria is a defining dysfunction of pre-eclampsia Proteinuria is one of the cardinal indications of pre-eclampsia, a common and severe complication in pregnancy. Also, there are several factors responsible for its occurrence among pregnant women. The study aimed to establish the occurrence of proteinuria among pregnant women and to establish the predisposing factors of proteinuria among pregnant women attending antenatal care services in St. Francis Hospital Nsambya.

Methodology:

This was a cross-sectional study where qualitative and quantitative data was collected. Participants' urine samples were taken off and analyzed macroscopically, protein detection using uristics, and $25 \%$ SSA and then microscopic examination done once they had consented.

Results:

Out of 96 participants, the occurrence of proteinuria was $9.4 \%(p=0.094)$ and it was increasing with the increase in the age of the pregnant women. The predisposing factors to proteinuria in pregnancy were urinary tract infections (88.9\%) $(p=0.889)$, hypertension $(11.1 \%)(p=0.111)$ and gestation age. Conclusion and recommendation:

Clients who receive antenatal care services in St. Francis Hospital Nsambya antenatal clinic should routinely be screened for proteinuria. Wider research about proteinuria among pregnant women should be done to establish a more nationalistic occurrence. Health education should emphasize the importance of pregnant women reporting urinary tract infections after being empowered with its signs and symptoms even without pain. This is because urinary tract infections can lead to complications in pregnancy and could become fatal.
\end{abstract}

\section{Background}

Proteinuria refers to a condition where more than trace amounts of proteins are found in normal urine (Cheesbrough et al.,1998). Proteinuria is a defining dysfunction of pre-eclampsia (Abebe et al., 2008). Urinary protein excretion is considered abnormal in pregnant women when it exceeds $300 \mathrm{mg} / 24$ hours at

\footnotetext{
${ }^{1}$ Corresponding author.

2E-mail: munyagaeddie@gmail.com

${ }^{3}$ E-mail: serunjogidavid16@gmail.com
} 
any time during gestation, a level that usually correlates with 1+ on urine dipstick. Proteinuria documented before pregnancy or before 20 weeks' gestation suggests preexisting renal disease. (Airoldi et al., 2007).

The symptoms of a person with proteinuria having active disease may include among others bone pain, excessive sleepness, neuropathy, if one has protein deposits in their fingers and toes due to their disease, oliguria, red-coloured urine, painful micturition, nausea or vomiting, some people experience loss of appetite. Proteinuria is associated with maternal and fetal complications in the case of a hypertensive pregnancy (Frusca, 2003).

A study carried out in Harrisburg Pa, USA showed that 202 pregnant women with no history of proteinuria with a mean age of $27 \pm 7$ years (range $15-44$ years) had significant proteinuria ( $\geq 1+$ protein) of $3.8 \%, 10.7 \%$, and $10.6 \%$ of dipstick tests performed in the first, second and third trimesters respectively. Hypertensive disorders were diagnosed in thirteen patients (6.4\%); three patients had chronic hypertension, two patients had preeclampsia, two patients had preeclampsia superimposed on chronic hypertension, and six patients had gestational hypertension. Obese patients were significantly more likely to develop one of the hypertensive disorders of pregnancy (OR 6.1; $P=0.04$ ) than other patients. These disorders tended to be more common among patients who tested positive for proteinuria $(\geq 1+)$ during the first trimester compared to patients with negative urine dipstick testing (OR 3.1; P $=0.3$ ) but the difference was not statistically significant. Proteinuria disappeared in all patients postpartum, and none of the patients had deterioration in kidney function (Osman, 2011).

A study done in Albania consisted of 470 pregnant women from Shkodra Region. Proteinuria was detected among $25.7 \%$ of the participants. While the prevalence of hypertension and diabetes resulted in $11.9 \%$ and $1.1 \%$ respectively. Proteinuria was higher in age groups $<24$ and $>35$ years old than in the other two groups. There was a statistically significant difference between the prevalence of proteinuria and trimesters. So proteinuria was higher in the third and second trimesters ( $33.5 \%$ and $23.8 \%$ respectively) comparing with the first trimesters (4.9\%). Age groups $<24$ and $>35$ years old increase likelihood of proteinuria 2.1 and 3.3 respectively (OR 2.1 and OR $3.3 p<0.05$ ) compared with women age groups $25-29$ years; women in the third and second trimester have more likely to develop proteinuria (OR 10.1 and OR $6.3 p<0.05$ ) than the women in the first trimester; parity-nulliparous increase likelihood of proteinuria 1.8 times (OR 1.8 p <0.05) compared with multiparous women (Lulzime Dhora, 2015).

Pre-eclampsia (PE) is a disorder of pregnancy characterized by the onset of high blood pressure and often a significant amount of protein in the urine (Eiland et al., 2012). Pre-eclampsia affects 2-8\% (p-value of $0.02-0.08$ ) of pregnancies worldwide (WHO recommendations, 2011). PE is diagnosed when a pregnant woman develops proteinuria $\geq 0.3$ grams (300 $\mathrm{mg}$ ) or more of protein in a 24-hour urine sample or a SPOT urinary protein to creatinine ratio $\geq 0.3$ or a urine dipstick reading of $1+$ or greater (dipstick reading should only be used if other quantitative methods are not available) (Hypertension in pregnancy report, 2013). Pre-eclampsia is an important cause of maternal morbidity and mortality in Nigeria. Twelve percent of all maternal death worldwide are due to hypertensive disorders of pregnancy and it has been shown that patients with significant proteinuria have a significant reduction in the mean birth weight for gestation age compared with hypertension alone due to intrauterine growth restrictions.

Proteinuria is a hallmark of many renal disorders and its detection helps the clinicians to determine if a significant renal disease is present. The standard method of measuring of urine protein excretion involves the determination of protein concentration in a timed urine collection (Curtis, 2004).

\section{METHODOLOGY}

\section{Study site}

The study was conducted at St. Francis hospital Nsambya OPD Department located along the old Ggaba road opposite St Peter's Secondary school before reaching Radio Sapientia. It is located on Nsambya Hill in the middle of Kampala, approximately 3 miles $(4.8 \mathrm{~km})$ southwest of the central business district. It is a referral hospital with a bed capacity of 361 beds. It is involved in patient care, research, and training.

\section{Study design}


It was a cross-sectional study where qualitative and quantitative data was collected. Both numerical and non-numerical data were collected.

\section{Study population}

This comprised all pregnant women who were attending the antenatal care clinic of St. Francis Hospital Nsambya during the time of the study.

\section{Selection criteria}

All pregnant women who were seeking antenatal services during the period of data collection were eligible for the study upon consenting.

Sample size

Sample size was calculated using the formula by (Leslie and Kish, 1965).

$\mathrm{n}=\mathrm{Z} 2 \mathrm{PQ}$

$\mathrm{d} 2$

Where; $\mathrm{n}=$ sample size needed

$\mathrm{Z}=$ standard deviation 1.96

$P=$ Occurrence of proteinuria (50\%),

$\mathrm{Q}=1-\mathrm{P}$

$\mathrm{d}=$ Aceptable error $10 \%$

$\mathrm{N}=(1.96) 2 \times 0.5 \times 0.5$

$(0.1) 2$

$\mathrm{n}=96$

Total of 96 women were selected for the study

\section{Sampling technique}

The study participants were selected by purposive simple random sampling till the desired number was attained.

\section{Laboratory procedure}

\section{Data collection and research tool}

A questionnaire was used to collect data from the study of women. Each of the clients was then asked to collect a urine sample in the clean $28 \mathrm{ml}$ universal bottle and these samples were analyzed by the researcher immediately. The results of the analysis were entered into the respective questionnaire.

\section{Quality control}

Known positive specimens were run alongside specimens to check on the performance of the uristix. The $\mathrm{pH}$ of the urine was checked to rule out false-positive results that could have arisen if the urine was alkaline.

The samples were also analyzed immediately they were obtained and those were delayed analysis was inevitable; they were kept in a refrigerator at 40C.

\section{Data analysis and management}

This was done manually. Data from each of the questionnaires were entered into a specially designed data collection sheet from where it was counted and entered into the computer. Herein, it was analyzed using an excel program to generate tables and figures

\section{Ethical consideration}

A letter of introduction to the management of St. Francis Hospital Nsambya was obtained from the school. Permission to conduct this study in $\mathrm{NH}$ antenatal clinic was then sought from the hospital management. All the information collected from the study women was treated with the utmost confidentiality. No names were used during data collection but instead, study numbers were used.

\section{Study limitations}

The researcher being a student with no source of income experienced a shortage of funds during the time of the study.

However, efforts were made and funds were solicited from relatives and friends which made the study a success. 
Table 1. Distribution of the pregnant women by their age

\begin{tabular}{lll}
\hline Age (in years) & Frequency & Percentage (\%) \\
Less than 18years & 6 & 6.3 \\
18-35yrs & 65 & 67.7 \\
36-45yrs & 20 & 20.8 \\
Above 45yrs & 5 & 5.2 \\
Total & $\mathbf{9 6}$ & $\mathbf{1 0 0}$ \\
\hline
\end{tabular}

Table 2. Distribution of study women by gestation age

\begin{tabular}{lll}
\hline Gestation age (in weeks) & Frequency & Percentage (\%) \\
$<30$ & 55 & 57.3 \\
$30-35$ & 24 & 25 \\
$36-40$ & 17 & 17.7 \\
Total & 96 & $\mathbf{1 0 0}$ \\
\hline
\end{tabular}

\section{Dissemination of results}

The research findings were compiled into a research report, copies of which were given to the University of Kisubi and St. Francis Hospital Nsambya administration. A copy was also retained by the researcher himself.

\section{SECTION A: BIO DATA}

\section{RESULTS}

bove shows that $65(67.7 \%)$ of the pregnant study women in the study were 18-35years old, 20 (20.8\%) were $36-45 y e a r s, 6(6.25 \%)$ were less than $18 y e a r s$ old and that $5(5.2 \%)$ were above $45 y e a r s$

\section{Figure 1: Bar graph showing distribution of study women according to their parity}

bove shows that $55(57.3 \%)$ of the mothers had a gestational age of under 30weeks, 24 (25\%) had pregnancies between 30 and 35 weeks and 17 (17.7\%) hadguestational ages between 36 and 40weeks.

\section{SECTION B: OCCURRENCE OF PROTEINURIA}

\section{Figure 2: Pie chart showing the occurrence of proteinuria among the study women}

bove shows that $2(40 \%)$ of the women above $45 y$ years of age had proteinuria whereas $3(64 \%)$ of the same age bracket didn't have proteinuria. It further shows that $5(25 \%)$ of the pregnant women aged 36-45years had proteinuria whereas $15(75 \%)$ didn't have it. $2(3.1 \%)$ of those aged 18-35years had proteinuria whereas $63(96.9 \%)$ didn't have the proteinuria. The table also shows that none of the pregnant women below 18years had proteinuria whereas all (100\%) of the pregnant women less than 18years never had proteinuria.

\section{SECTION C: PREDISPOSING FACTORS OF PROTEINURIA}

Table 3. Proteinuria by age group of the pregnant women

\begin{tabular}{llll}
\hline Age (in years) & Had proteinuria & Didn't have proteinuria & Total \\
Less than 18years & $0(0 \%)$ & $6(100 \%)$ & 6 \\
18-35yrs & $2(3.1 \%)$ & $63(96.9 \%)$ & 65 \\
36-45yrs & $5(25 \%)$ & $15(75 \%)$ & 20 \\
Above 45yrs & $2(40 \%)$ & $3(64 \%)$ & 5 \\
Total & $\mathbf{9}$ & $\mathbf{8 7}$ & 96 \\
\hline
\end{tabular}




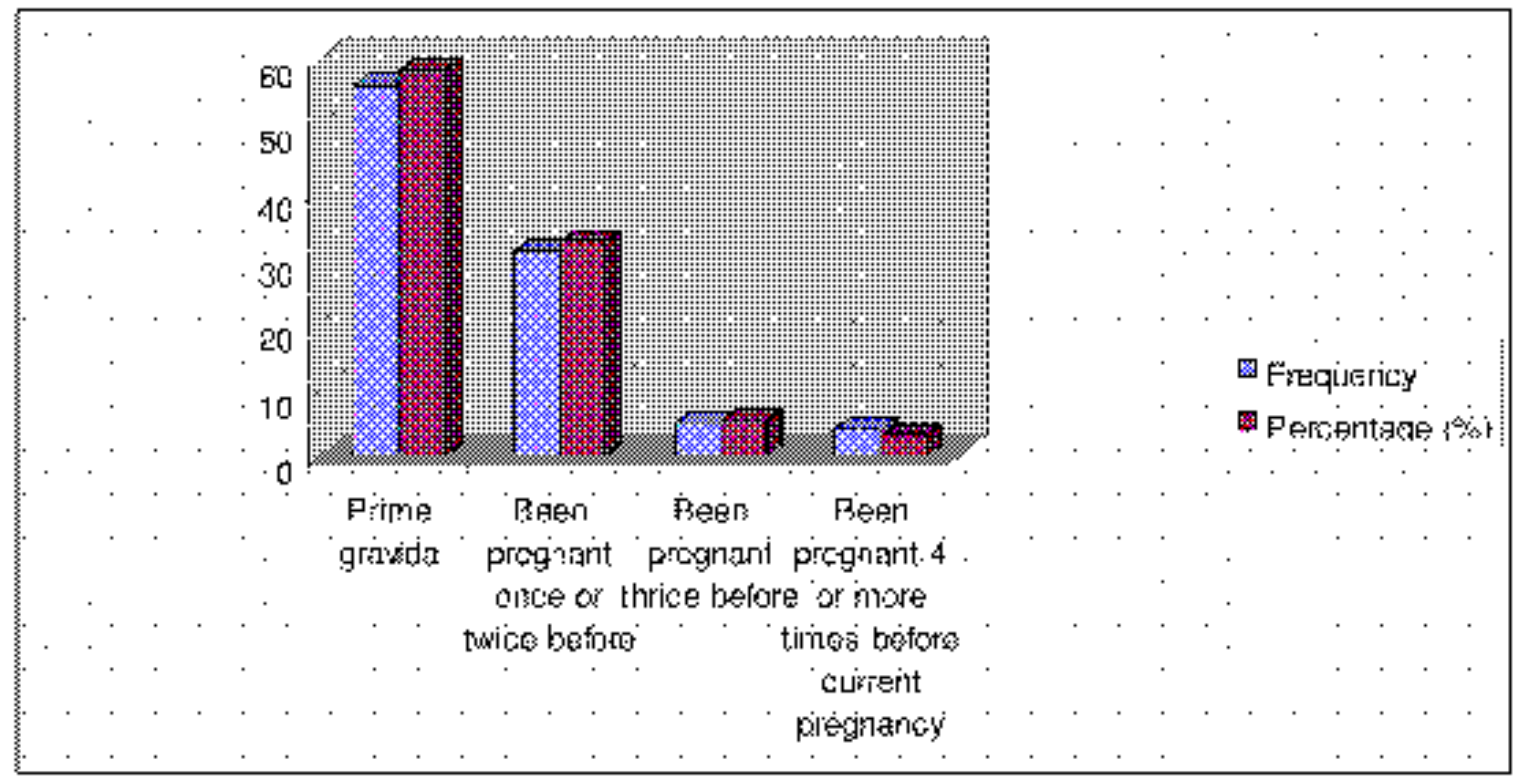

Figure 1. bove shows that 56 (58.3\%) of the study women were pregnant for the first time, that 31 (32.3\%) had been pregnant once or twice before their current pregnancy at the time of study, that $5(5.2 \%)$ had been pregnant three times before the pregnancy they were carryingcarrying at the time of the study and that 4 (3.1\%) were carrying their fifth pregnancy and above 


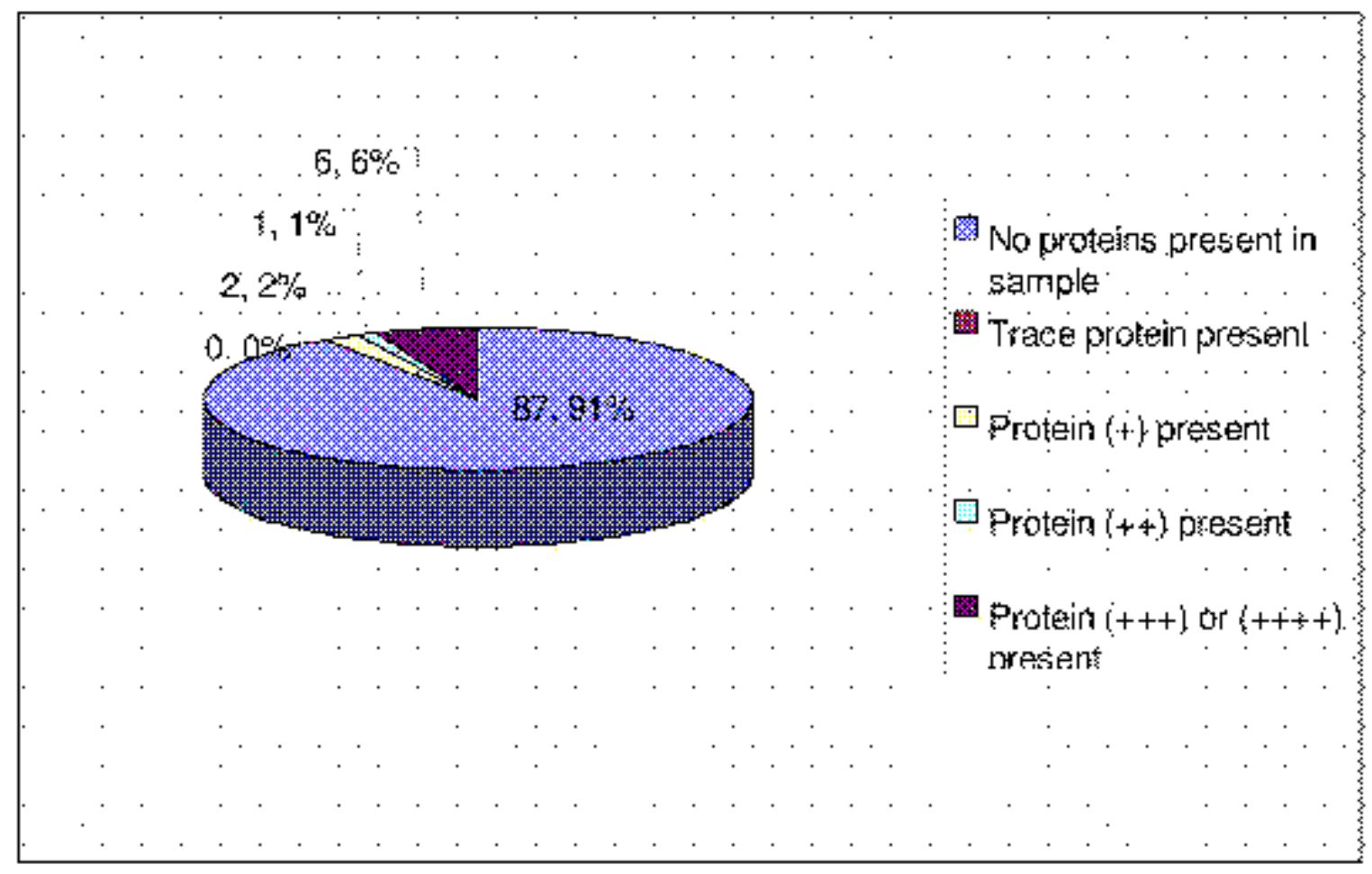

Figure 2. bove shows that $87(90.6 \%)$ of the study women did not have proteinuria at the time of conducting the study, $6(6.3 \%)$ had a proteinuria of plus three or four, $2(2.1 \%)$ had a proteinuria of plus one, $1(1.0 \%)$ had proteinuria (+) and none (0\%) had a trace proteinuria. 
Table 4. Mothers on whether they had a known renal disease

\begin{tabular}{lll}
\hline & Frequency & Percentage \\
Had known renal disease & 0 & 0 \\
Didn't have a known renal disease & 96 & 100 \\
Total & 96 & 100 \\
\hline
\end{tabular}

Table 5. Mothers on whether they had Fever

\begin{tabular}{lll}
\hline & Frequency & Percentage \\
Had fever & 3 & 3.1 \\
Didn't have fever & 93 & 96.9 \\
Total & $\mathbf{9 6}$ & $\mathbf{1 0 0}$ \\
\hline
\end{tabular}

bove shows that all the 96 pregnant study women didn't have a renal disease and none (0\%) had the disease

bove shows that 93 (96.9\%) of the pregnant study women were not having fever and $3(3.1 \%)$ had fever.

bove shows that 94 (97.9\%) of the pregnant women in the study declared that they never had hypertension and $2(2.1 \%)$ said they had hypertension

Figure 4: Bar graph showing the study women's' BP measurement for the day

Figure 5: Bar graph showing hypertension by gestation age of the study women

bove shows that $64(66.7 \%)$, never had any abnormality in their urine deposits, 30 (31.3\%) had pus cells/rbcs/epithelial cells (+ or more) seen, $1(1 \%)$ had yeast cells/ Trichomonas vaginalis trophozoites seen and $1(1 \%)$ had hyaline/granular casts seen

bove shows that $8(88.9 \%)$ of the proteinuria was amongst women with abnormal urinary deposits pointing to urinary tract infections, $1(11.1 \%)$ was among hypertensive women with high blood pressure above $140 / 90 \mathrm{mmHg}$, none (0\%) had either renal disease or diabetes mellitus or fever

\section{Biodata}

\section{DISCUSSION, CONCLUSIONS, AND RECOMMENDATIONS}

This chapter presents findings from 96 pregnant women, 65 (67.7\%) of whom were 18-35years old, 20 (20.8\%) were 36-45years, 6 (6.25\%) were less than 18years old, and $5(5.2 \%)$ were above $45 y e a r s$ of age.

$56(58.3 \%)$ of the study women were pregnant for the first time, 31 (32.3\%) had been pregnant once or twice before their current pregnancy at the time of the study, $5(5.2 \%)$ had been pregnant three times before the pregnancy they were carrying, at the time of the study and 4 (3.1\%) were carrying their fifth pregnancy and above

$55(57.3 \%)$ of the pregnant study women had a gestational age of under 30weeks, 24 (25\%) had pregnancies between 30 and 35 weeks old and $17(17.7 \%)$ had gestational ages between 36 and 40weeks.

\section{Occurrence of proteinuria}

$9(9.4 \%)$ of the study women had proteinuria at the time of conducting the study. Expressed as of the total population, $6(6.3 \%)$ had proteinuria of plus three or four, $2(2.1 \%)$ had proteinuria of plus one, 1

Table 6. Mothers on whether they were known hypertensive

\begin{tabular}{lll}
\hline & Frequency & Percentage \\
Had hypertension & 2 & 2.1 \\
Didn't have hypertension & 94 & 97.9 \\
Total & 96 & $\mathbf{1 0 0}$ \\
\hline
\end{tabular}




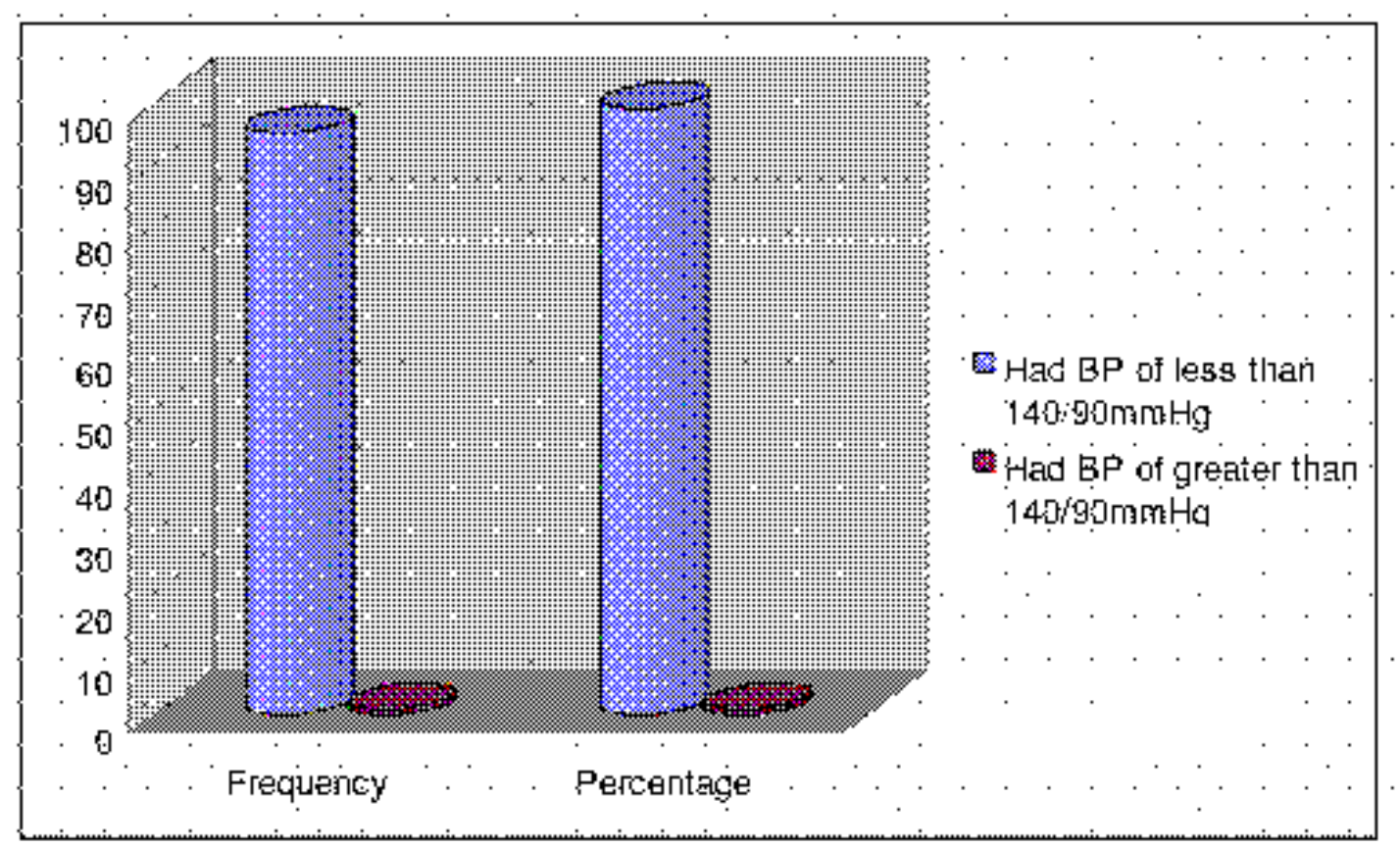

Figure 3. bove shows that $95(99.0 \%)$ of the pregnant study women had a blood pressure of less than $140 / 90 \mathrm{mmHg}$ and 1 (1.0\%) had a blood pressure of greater than $140 / 90 \mathrm{~mm} / \mathrm{Hg}$ 


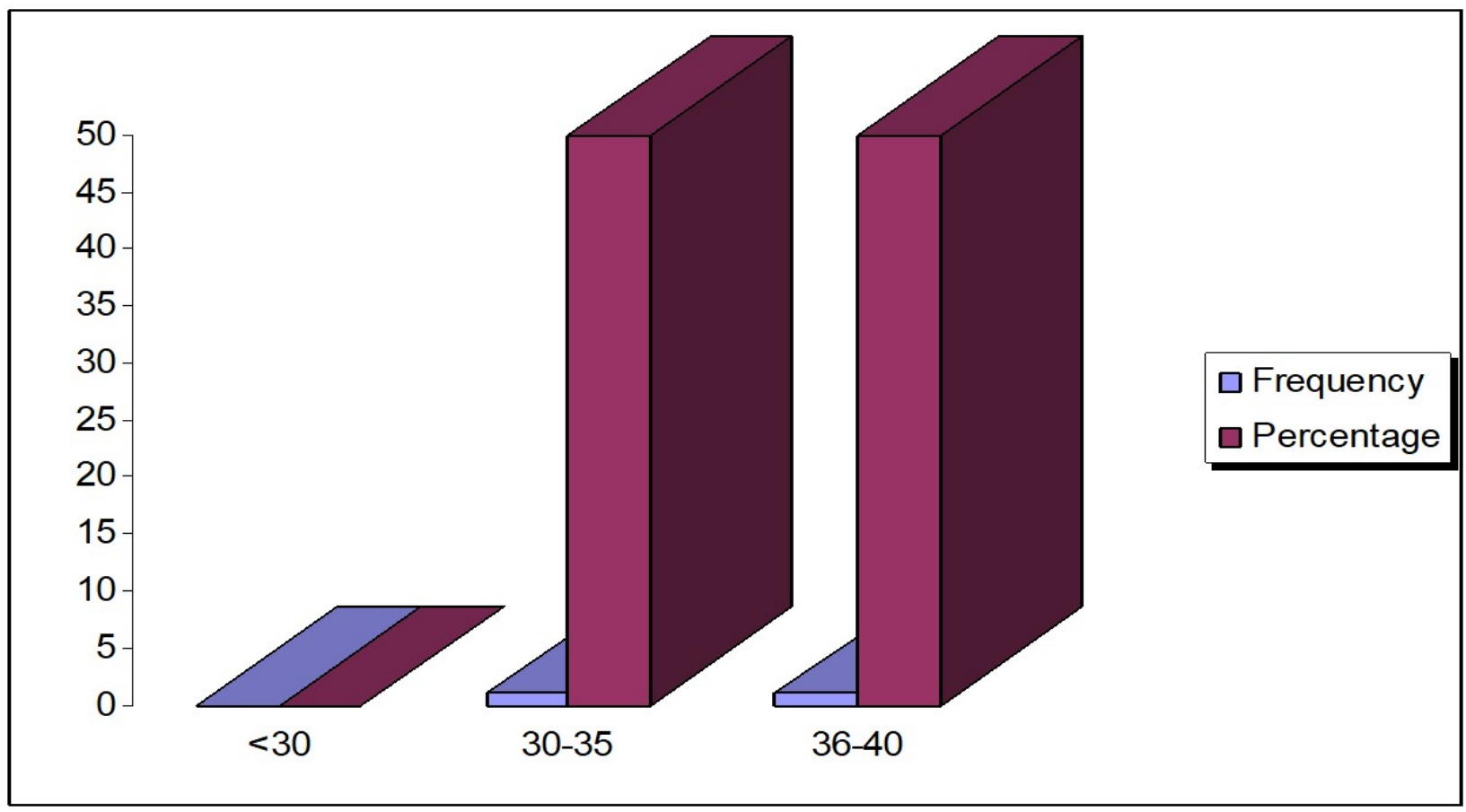

Figure 4. bove shows that 1 (50\%) of the pregnant hypertensive women in the study had a gestation age of 30-35weeks, 1 (50\%) had one of 36-40weeks and none had hypertension below 30weeks of gestation.

Table 7. Mother's urinary microscopy results

\begin{tabular}{lll}
\hline Protein findings in urine & Frequency & Percentage \\
No abnormality detected & 64 & 66.7 \\
Pus cells/rbcs/epithelial cells seen (+ or more) & 30 & 31.3 \\
Yeast cells/ Trichomonas vaginalis trophozoites seen & 1 & 1 \\
Hyaline/granular casts seen & 1 & 1 \\
Total & $\mathbf{9 6}$ & $\mathbf{1 0 0}$ \\
\hline
\end{tabular}

Table 8. Proteinuria related with predisposing factors

\begin{tabular}{lll}
\hline & Frequency & Percentage \\
Had abnormal urinary deposit & 8 & 88.9 \\
Had hypertension with a BP of $>140 / 90 \mathrm{mmHg}$ and a gestation age $>30$ weeks & 1 & 11.1 \\
Had DM & 0 & 0 \\
Renal disease & 0 & 0 \\
Fever & 0 & 0 \\
Total & $\mathbf{9}$ & $\mathbf{1 0 0}$ \\
\hline
\end{tabular}


$(1.0 \%)$ had proteinuria (+) and none $(0 \%)$ had trace proteinuria. This is a comparable finding with that of $10 \%$ proteinuria occurrence found by Waugh et al., (2004).

The proteinuria occurrence finding of $3.8 \%$ by William A (2006), though a little lower is comparable with this study's findings of $9.4 \%$ proteinuria occurrence but certainly much lower than the projection 0 f $40.8 \%$ for all women at one point during their pregnancy.

$2(40 \%)$ of the women above 45years of age, $5(25 \%)$ of those aged 36-45years, $2(3.1 \%)$ of those aged 18-35years, and none of the pregnant women below 18years had proteinuria. The proteinuria seems to have increased with an increase in the age of the pregnant women.

\section{Predisposing factors}

$8(88.9 \%)$ of the pregnant women with proteinuria had abnormal urinary deposits pointing to urinary tract infections. This is in agreement with the projection of Gregory F et al., (2005) that pathological proteinuria may be caused by urinary and non-urinary abnormalities. It is also in agreement with the findings of Waugh et al., (2004) that non-renal proteinuria is most frequently associated with lower urinary tract infection or hemorrhage

$1(11.1 \%)$ of the pregnant women were hypertensive with a high blood pressure of above $140 / 90 \mathrm{mmHg}$. This finding is much higher than that of Frasca et al., (2003), who found the occurrence of pregnancyinduced hypertension with and without proteinuria as $2.3 \%$ and $4.3 \%$ respectively. It is further in agreement with the findings of Waugh et al., (2004) that proteinuria is common in women after 20weeks of gestation.

32 (33.3\%) of the pregnant study women had pus cells/RBCs/epithelial cells (+ or more) in their urine deposits or had yeast cells/ Trichomonas vaginalis trophozoites and or had hyaline/granular casts seen in their urinary deposits

None $(0 \%)$ of the study women had either renal disease or diabetes mellitus or fever. This is not in conformity with the projection by Gregory et al., (2005) that strenuous exercise, seizures, fever, exposure to extensive heat or cold, and stress may cause physiological proteinuria.

Given that none of the study women with proteinuria had diabetes mellitus or kidney disease, it shows that the proteinuria was not due to these disease conditions as was highlighted by Sibai et al., (1998) that 20 to 25 percent of women with chronic hypertension and diabetes develop superimposed preeclampsia

\section{Conclusions}

The occurrence of proteinuria was $9.4 \%$ and it was increasing with the increase in the age of the pregnant women.

The predisposing factors to proteinuria in pregnancy were urinary tract infections (88.9\%), hypertension (11.1\%), and gestation age.

\section{Recommendations}

Clients who receive antenatal care services in St. Francis Hospital Nsambya antenatal clinic should routinely be screened for proteinuria as well to check for the onset of pre-eclampsia irrespective of the number of antenatal care (ANC) visits they have had.

Wider research about proteinuria among pregnant women should be done to establish a more nationalistic occurrence.

Health education should emphasize the importance of pregnant women reporting urinary tract infections after being empowered with its signs and symptoms even without pain.

\section{References:}

1). "Hypertension in pregnancy. Report of the American College of Obstetricians and Gynecologists' Task Force on Hypertension in Pregnancy." Obstet Gynecol. 122 (5): 1122-31. Nov 2013

2). Abebe J., Eigbefoh J., Isabu P., Okogbenin S., Eifediyi R., \& Okusanya B. (2008). Accuracy of urine dipsticks, 2-h and 12-h urine collections for protein measurement as compared with the 24-h collection. J Obstet Gynaecol. 28: 496-500. 
3). Airoldi J., \& Weinstein L. (2007). Clinical significance of proteinuria in pregnancy. Obstet Gynecol Surv. 2007 Feb;62(2):117-24. Department of Obstetrics and Gynecology, Thomas Jefferson University, Philadelphia, Pennsylvania 19107, USA.

4). Cheesbrough M. (1998), District laboratory practice in Tropical Countries part 1, Cambridge

5). Curtis S. (2004), Evaluation of proteinuria in pregnant women http//www.uptodate.com/patientscon tents.com.

6). Eiland., Elosha., Nzerue., Chike., Faulkner., \& Marquetta. (2012). "Preeclampsia 2012". Journal of Pregnancy.1-7.

7). Frasca T. (2003) Urinary levels of protein in pregnancy included hypertension.

8). Frusca T. (2003), Importance of proteinuria hypertension in pregnancy http;//eat.inist.fr/?amodete=affiche N 8 CP sidt $=3481658$.

9). Gregory F. (2005) Causes of my patient's proteinuria, www.Iriskidney.com/education/en/education 03. stml.Osman O., Bakare AO., \& Elamin S., (2011). The prevalence of proteinuria among pregnant women as detected by a semi-quantitative method: a single center experience. Arab J Nephrol Transplant. May; 4(2):77-82.

10). Lulzime Dhora.,\& Mirela Lika, (2015). Risk factors for proetenuria in pregnancy. International Journal of Technical Research and Applications.

11). Monica Cheesbrough, (2006). District Laboratory Practice in Tropical countries, Part 1, 2nd edition.

12). Osman O., Bakare AO., \& Elamin S., (2011). The prevalence of proteinuria among pregnant women as detected by a semi-quantitative method: a single center experience. Arab J Nephrol Transplant. May; 4(2):77-82.

13). Sibai BM., Lindheimer M., \& Hauth J. (1998). Risk factors for preeclampsia, abruptio placentae, and adverse neonatal outcomes among women with chronic hypertension. National Institute of Child Health and Human Development Network of Maternal-Fetal Medicine Units. N Engl J Med 339:667.

14). Waugh J. (2004). Fetal and maternal medical review, http;//www.sonals.cambridge.org/download.p hp.

15). WHO. (2011). Recommendations for prevention and treatment of pre-eclampsia and eclampsia.

16). William A. (2006), proteinuria as a predictor for pre-eclampsia http;//www.jp fomilins.com/pages.asp $p$ and $=2812$ WD. 